\title{
Amplified Electrochemical Sensor for Nano-molar Detection of Morphine in Drug Samples
}

Samad Jafari Zare ${ }^{1}$, Mojtaba Masomi $^{1 *}$, Mazyar Sharifzadeh Baei ${ }^{1}$, Shahram Naghizadeh Raeisi ${ }^{2}$ and Seyed-Ahmad Shahidi ${ }^{2}$

${ }^{1}$ Department of Chemical Engineering, Ayatollah Amoli Branch, Islamic Azad University, Amol, Iran

${ }^{2}$ Department of Food Science and Technology, Ayatollah Amoli Branch, Islamic Azad University, Amol 46311-39631, Mazandaran, Iran

*E-mail: mojtabamasomi@yahoo.com

doi: $10.20964 / 2021.01 .41$

Received: 8 September 2020 / Accepted: 20 October 2020 / Published: 30 November 2020

In this research, carbon paste electrode (CPE) was modified with $\mathrm{MgO} / \mathrm{SWCNT}$ nanocomposite and 1methyl-3-octylimidazolium tetrafluoroborate (MOCITFB) and then used as a highly sensitive analytical approach for the determination of morphine in drug samples. In this study, the MgO/SWCNTs was synthesized using the simple precipitation method. The TEM image displayed the decoration of $\mathrm{MgO}$ nanoparticles with diameter $\sim 40 \mathrm{~nm}$ at surface of SWCNTs. In addition, the electrochemical behavior of morphine was also investigated at surface of $\mathrm{MgO} / \mathrm{SWCNTs} / \mathrm{MOCITFB} / \mathrm{CPE}$ with different $\mathrm{pH}$ values. The findings displayed an electro-oxidation mechanism in the presence of one electron and one proton. Moreover, the oxidation signal of morphine showed a linear calibration curve in the concentration range of $3.0 \mathrm{nM}$ to $320 \mu \mathrm{M}$ with the detection limit pf $0.8 \mathrm{nM}$ at surface of $\mathrm{MgO} / \mathrm{SWCNTs} / \mathrm{MOCITFB/CPE}$. Moreover, the MgO/SWCNTs/MOCITFB/CPE was successfully used for the determination of morphine in injection sample with recovery range of $98.41 \%$ to $102.49 \%$.

Keywords: Morphine, MgO/SWCNTs, 1-methyl-3-octylimidazolium tetrafluoroborate, Nanocomposite, Modified sensor

\section{$\underline{\text { FULL TEXT }}$}

(C) 2021 The Authors. Published by ESG (www.electrochemsci.org). This article is an open access article distributed under the terms and conditions of the Creative Commons Attribution license (http://creativecommons.org/licenses/by/4.0/). 